\title{
Ensaio fílmico, eterno devir: projeto de filme inacabado e de um cinema futuro
}

\author{
Gabriela Machado Ramos de Almeida*
}

Resumo: O artigo apresenta uma discussão de caráter teórico sobre a constituição de um campo de estudos para o cinema de ensaio. A partir de um levantamento que identifica um devir-ensaio na prática e nas teorias do cinema desde a década de 1940 , o trabalho mapeia também os estudos recentes mais relevantes para a efetiva constituição do filme-ensaio como forma autônoma ou "quarto domínio do cinema" (Teixeira, 2015). Por fim, é apresentado um entendimento de ensaio fílmico que dialoga com as contribuições de autores como Català (2005 e 2014) e Corrigan (2015).

Palavras-chave: ensaio fílmico; cinema de não-ficção; teorias do cinema.

Resumen: El artículo presenta una discusión de carácter teórico sobre la constitución de un campo de estudios para el ensayo cinematográfico. Partiendo de un análisis que identifica un devenir-ensayo en la práctica y en las teorías del cine desde la década de 1940, el trabajo cartografa también los estudios recientes más relevantes para la efectiva constitución del filme-ensayo como forma autónoma o "cuarto dominio del cine" (Teixeira, 2015). Por último, se presenta una noción de ensayo fílmico que dialoga con las contribuciones de autores como Català (2005 y 2014) y Corrigan (2015).

Palabras clave: ensayo fílmico; cine de no ficción; teorías del cine.

Abstract: This paper presents a theoretical discussion about the constitution of a field of studies for the essay film. This research identifies a becoming-essay in both practice and theory of cinema since the 1940s. I also propose a mapping of recent and relevant studies which support the effective constitution of the film essay as an autonomous form or the "fourth domain of cinema"(Teixeira, 2015). Finally, I present a notion of film essay that dialogues with the contributions of authors such as Català (2005 and 2014) and Corrigan (2015).

Keywords: film essay; non-fiction film; film theory.

Résumé : Cet article présente une discussion théorique à propos de la constitution d'un champ d'études sur l'essai filmique. À partir d'une recherche qui veut mettre en évidence un tournant dans la pratique et dans les Théories du Cinéma depuis les années 1940, ce travail a aussi pour but de réunir les études plus récentes et considérées comme les plus pertinentes pour la constitution effective du film-essai comme une forme autonome ou le "quatrième domaine du cinéma"(Teixeira, 2015). Finalement, une notion d'essai de film est proposée en dialogue avec quelques auteurs tels que Català (2005 et 2014) et Corrigan (2015).

Mots-clés : film-essai ; cinéma de non-fiction ; théories du cinéma.

* Universidade Luterana do Brasil - Ulbra, Curso de Comunicação Social. 92425900, Canoas, Rio Grande do Sul, Brasil. E-mail: gabriela.mralmeida@gmail.com

Submissão do artigo: 25 de junho de 2018. Notificação de aceitação: 7 de agosto de 2018 . 


\section{Introdução}

O ensaio, desde as suas origens na literatura, costuma ser categorizado como a mais livre, a mais fugidia das formas de reflexão. Não propõe respostas acabadas, mas a inquietação, a abertura, a dúvida. Em função de características imanentes que parecem inviabilizar a sua categorização como um gênero narrativo em sentido estrito, o ensaio costuma ser definido a partir de negativas ou de um entendimento frouxo de que se trata de uma forma expressiva em que tudo vale ou, principalmente, que carece de rigor.

Embora seja possível identificar um devir-ensaio no cinema desde as suas primeiras décadas, e nas Teorias do Cinema pelo menos a partir da década de 1940, com Hans Richter e Alexandre Astruc, é sobretudo nos últimos vinte anos que ganha força a produção de ensaios fílmicos, no seio do que se pode caracterizar como uma virada subjetiva do documentário. É a partir desse contexto que passam a ser classificadas como ensaísticas obras como os filmes mais recentes de João Moreira Salles e, retrospectivamente, parte significativa da filmografia de cineastas como Agnès Varda, Chris Marker, Jean-Luc Godard e Harun Farocki. Embora, também, o filme-ensaio não seja necessariamente um braço do documentário, a sua vinculação ao cinema de não-ficção acabou tornando esse tipo de produção objeto de interesse prioritário de pesquisadores do cinema não-ficcional no Brasil.

No campo dos estudos do cinema, especialmente do documentário, o termo "ensaio fílmico" vem sendo utilizado como chave de leitura para um conjunto de obras marcadas por características como a autorreflexão, a metalinguagem, o uso crítico do dispositivo cinematográfico e um certo teor autobiográfico. Não raro, a expressão também designa filmes de difícil classificação, tornando o ensaio uma grande categoria que abarcaria diferentes formas de produção não-ficcional mais ou menos afastadas do cânone do documentário e dos seus principais modos de representação institucionalizados, como o expositivo, o observacional e o participativo, bem como do cinema experimental.

Se uma genealogia do filme-ensaio localizará no documentário as suas origens, pretendo com esse texto avançar numa discussão sobre os ensaios fílmicos que não se restrinja ao campo do documentário e que pense possibilidades e sensibilidades ensaísticas no cinema em diferentes momentos do século XX e também neste início do século XXI. Assim, considero essencial a revisão de um conjunto de estudos produzidos em diferentes momentos e que, de algum modo, contribuem para a aproximação ao ensaio fílmico que é feita aqui, em um movimento que respeita a natureza incerta do fenômeno e a experiência de desorientação e deriva que a sua fruição costuma provocar. 
Esta revisão também é necessária pois este trabalho se insere num campo ainda em construção nos estudos de cinema no Brasil, apoiado numa relação que pretendo estabelecer entre três pilares: 1) a afirmação do cinema como possibilidade de pensar com e por imagens e o ensaio como sua materialização; 2) as experiências de produção de obras audiovisuais que não apenas esgarçam fronteiras de gênero, mas também obrigam a repensar a linguagem audiovisual, os dispositivos e os modos de exibição e 3) a pertinência de pensar em uma sensibilidade ou uma inflexão ensaísticas que se fazem presentes em obras diversas, inclusive algumas situadas no cânone do documentário.

\section{O ensaio fílmico em devir nas Teorias do Cinema}

O ensaio fílmico costuma ser associado a um certo teor vanguardista, à renovação e à ousadia no manejo da linguagem audiovisual e dos dispositivos. Com alguma frequência, o estudo de obras classificadas como ensaísticas se detém excessivamente na importância do texto verbal ou escrito presente nos filmes como linha condutora do pensamento das instâncias autoral e narrativa, embora a aproximação direta entre ensaios fílmicos e a literatura varie bastante de obra para obra ${ }^{1}$ e não seja o propósito aqui analisar a tradução, transposição ou adaptação do ensaio literário ao cinema.

Os ensaios literário e fílmico aproximam-se principalmente no que se refere à forma, entendida aqui como a sua expressão materializada num todo observável, seja ele um texto ou um filme. Ambos situam-se eternamente numa espécie de entre-lugar ou num "entre-gêneros", já que não parecem autorizar filiação a gênero algum e menos ainda pretendem constituir-se eles mesmos como gêneros autônomos, dotados de demarcações internas mais rígidas.

A bibliografia disponível em torno do assunto é restrita, mas vem crescendo em número nos últimos anos. A maior parte das poucas obras existentes ainda não foi traduzida para o português, sendo acessíveis apenas em seus idiomas de origem, como os livros L'Essay et le cinema (2004), organizado por Suzanna Liandrat-Guigues e Murielle Gagnebin; The Personal Camera: subjective cinema and the essay film (2009), de Laura Rascaroli, e Estética

1. As diferenças estilísticas entre os filmes citados acima permitem notar este fato. Noite e Neblina, por exemplo, tem narração baseada em um texto altamente poético e ao mesmo tempo impactante do escritor Jean Cayrol, um sobrevivente de campo de concentração. Já Videogramas de uma Revolução não tem narração e conta com textos escritos explicativos que aparecem no filme na forma de lettering, para fornecer ao espectador algumas informações contextuais sobre as imagens que estão sendo exibidas. Neste caso, não é o texto que fornece à obra o seu caráter de ensaio, mas sim a forma como a reflexão está inscrita nas próprias imagens e no fluxo de pensamento que elas geram. 
del ensayo: la forma ensayo, de Montaigne a Godard (2014), de Josep Maria Català. $^{2}$

No entanto, embora seja comum aos autores associar o ensaísmo audiovisual às experiências recentes no terreno do cinema, uma genealogia das práticas cinematográficas que outrora foram classificadas como vanguardistas ou experimentais, e a revisão de alguns escritos e obras que buscavam afirmar outras potências para as imagens em movimento, além da representação e da narrativa, revelarão que esta vontade de expandir as possibilidades do cinema já se fez presente em momentos passados, e manifestou-se principalmente em duas vertentes que dialogam entre si: 1) o potencial do cinema como locus para expressão de pensamento e de saberes a respeito do mundo histórico, e 2) a noção de cinema expandido, que aproxima o cinema das artes especialmente a partir do surgimento do vídeo, abrindo caminho para que possamos nos referir a "ensaio audiovisual", englobando, assim, obras que escapam ao domínio exclusivo do cinema.

O pintor e cineasta vanguardista alemão Hans Richter foi quem primeiro referiu-se a um novo tipo de cinema que poderia tornar perceptíveis problemas, pensamentos e até ideias, e que daria visibilidade ao que não é visível, num texto chamado El ensayo fílmico: una nueva forma de la película documental $^{3}$, publicado em 1940. Segundo Richter, o desafio do documentário, sobretudo a partir de Robert Flaherty, era dar forma ao que chama de "conteúdo intelectual". $\mathrm{O}$ autor estabelece uma relação direta entre a complexidade de determinados assuntos e a dificuldade - ou mesmo impossibilidade - de abordá-los nos filmes de narrativa mais convencional. Para Richter, nem todo assunto é passível de transformar-se em discurso fílmico por meio de modelos didático-expositivos que buscam documentar algo fornecendo meramente uma cronologia de fatos. Assim, alguns temas demandariam um tratamento ensaístico. A contribuição do autor vai se tornando mais rica à medida que afirma:

Visto que no ensaio fílmico não se está sujeito à reprodução das aparências externas ou de uma série cronológica, e, ao contrário, se há de integrar ma-

2. Em outros casos é ainda mais difícil ter acesso à bibliografia, a exemplo de um título relevante que não teve lançamento comercial e cuja circulação é totalmente restrita: La forma que piensa. Tentativas en torno al cine-ensayo (2007), organizado por Antonio Weinrichter. Trata-se de uma coletânea lançada por ocasião do evento Punto de Vista - Festival Internacional de Cine Documental de Navarra, Espanha. Estão compilados neste livro diversos artigos, que passaram por um rico esforço de seleção e tradução para o espanhol.

3. Texto traduzido do alemão para o espanhol e publicado no livro organizado por Weinrichter (2007). Título original: Der Filmessay: eine neue Form des Dokumentarfilms (publicado no jornal alemão Nationalzeitung em 1940 e, posteriormente, na coletânea dedicada ao filmeensaio organizada por Christa Blümlinger e Constantin Wulff). Referência: Blüminger, C. \& Wulff, C. (orgs.). Schreiben Bilder Sprechen: Texte zum essayistischen film. Vienna: Sonderzahl, 1992. 
terial visual de procedências variadas, pode-se saltar livremente no espaço e no tempo: por exemplo, da reprodução objetiva à alegoria fantástica, e dela a uma cena interpretada; pode-se utilizar tudo, o que existe e o que se inventa, desde que sirva como argumento para tornar visível o pensamento de base. (Richter, 2007: 188, tradução nossa).

Richter encerra afirmando que o cinema pode interferir criativamente no mundo da representação do seu tempo e deixa uma provocadora questão: "Esta não seria uma meta a desejar ardentemente?". (Richter, 2007: 189, tradução nossa). O tom de todo o texto e a pergunta são premonitórios, e o que Richter desejava vai passar a acontecer poucos anos depois da publicação do seu escrito, a partir da virada para o cinema moderno, especialmente com Roberto Rossellini.

Também bastante premonitório é o teor dos escritos de Alexandre Astruc no artigo embrionário da "política dos autores", Nascimento de uma nova vanguarda, a câmera-caneta, publicado originalmente em 1948. Astruc afirma que o cinema finalmente está se tornando uma linguagem, um meio de expressão como são todas as outras artes:

Depois de ter sido sucessivamente uma atração de feira, uma diversão parecida com o teatro de boulevard, ou um meio de conservar as imagens da época, [o cinema] se converte pouco a pouco em uma língua. Uma linguagem, a saber, uma forma na qual e mediante a qual um artista pode expressar seu pensamento, por mais abstrato que seja, ou traduzir suas obsessões exatamente do mesmo modo como ocorre atualmente com o ensaio ou o romance. (Astruc, 2010: 221, tradução nossa).

Astruc cunha, então, o termo "Câmera-caneta" ("Caméra-stylo") e a partir dele sugere que o cinema conseguirá se desvencilhar da "tirania do visual, da imagem pela imagem" para tornar-se um meio de escritura tão flexível e sutil como a linguagem escrita (Astruc, 2010: 221). E não apenas isso: para o autor, certas ideias e visões de mundo de campos tão distintos quanto a metafísica, a produção humana, a psicologia e as paixões são de tal natureza que apenas o cinema poderia descrevê-las.

O cinema aparece, deste modo, não só como uma escritura possível para o tratamento de determinadas questões, mas, principalmente, como um ambiente privilegiado para certas formulações. Astruc chega a afirmar que, se Descartes tivesse que escrever o Discurso do Método na década de 1940, o faria com uma câmera $16 \mathrm{~mm}$ e filme, pois apenas por meio do cinema poderia expressar-se de forma apropriada. E, para Astruc, o cinema poderia gerar obras equivalentes, em profundidade e significado, aos romances de Faulkner e de Malraux e aos ensaios de Sartre e Camus: "o autor escreve com a sua câmera da mesma 
forma que o escritor escreve com sua estilográfica" - trata-se, assim, de uma "autêntica escritura". ${ }^{4}$ (Astruc, 2010: 224, tradução nossa).

Astruc aproveita também para criticar a postura e o discurso das vanguardas e para rejeitar qualquer tentativa de defesa de um cinema "puro", como fizeram algumas vanguardas históricas ao propor que poderia haver um terreno exclusivo do cinema: "[...] ao contrário, pretendemos estendê-lo e convertêlo na linguagem mais vasta e mais transparente possível" (Astruc, 2010: 224, tradução nossa). Acusa o Surrealismo de tentar adaptar ao cinema as investigações da pintura e da poesia e afirma que "entre o cinema puro dos anos vinte e o teatro filmado, segue existindo espaço para um cinema livre". (Astruc, 2010: 223, tradução nossa).

As proposições de Astruc me parecem pertinentes por três motivos fundamentais. Em primeiro lugar, por propor lá em 1948 que existem uns cinemas, e não apenas um cinema. Em segundo lugar, por antecipar, ainda que de maneira não intencional, a ideia de cinema expandido e do borramento das fronteiras entre o cinema e outras artes ${ }^{5}$, e, em terceiro lugar, por afirmar uma qualidade dialética para o cinema e situá-lo como uma espécie de mecanismo relacional entre diversos saberes.

Também entre os franceses ou autores que estabeleceram sua produção intelectual na França, André Bazin e Noel Burch dedicaram alguma atenção à relação entre ensaio e cinema. No caso de Bazin, analisando o filme Carta da Sibéria (1957), de Chris Marker, em texto publicado na revista France Observateur, em 1958, em que descreve a obra como "um ensaio documentado por meio do filme" (Bazin apud Rascaroli, 2008, tradução nossa). Já Burch fala de uma categoria de filmes, chamados de "filme-meditação", que expõem teses e antíteses em sua própria tessitura. Para o autor, Jean-Luc Godard seria um ensaísta em um sentido totalmente novo, que só justificaria plenamente no cinema: "Um cinema de meditação pura, onde o tema é a base de uma construção intelectual suscetível de transformar-se na forma, na própria realização, sem que esta seja, por isso, edulcorada ou alterada". (Burch, 2008: 192-193).

O discurso de Burch converge com o dos outros autores trazidos aqui até agora em um aspecto principal: a afirmação de que não apenas o cinema é um tipo de escritura passível de expor um pensamento complexo, mas, sobretudo, que é uma expressão privilegiada para este propósito. O interesse da crítica francesa deste período pelo tema é plenamente justificável, uma vez que boa parte dos primeiros filmes aos quais se associou a noção de ensaio

4. Procedimento para o qual Agnès Varda cunharia, alguns anos depois, a expressão "cinescrita" ("Cinécriture").

5. Para além das relações mais notadas e que sempre existiram entre o cinema e o teatro, ou entre o cinema e a literatura. 
foi produzida por cineastas como por Marker, Varda, Godard e Alain Resnais, na França do pós-guerra. Alguns autores, como Phillip Lopate (1996), Paul Arthur (2003) e Michael Renov (2005), com razão incluem ainda Jean Rouch entre os cineastas que produziram filmes com inflexão ensaística a partir da década de 1950, especialmente pela forma altamente reflexiva como Rouch usou o comentário (de pós-produção) em filmes como Os Mestres Loucos (1955) e Crônica de um Verão (Jean Rouch e Edgar Morin, 1960).

É possível apontar, neste conjunto de escritos mencionados, uma espécie de "devir-ensaio", o vislumbramento de uma potência ensaística para o cinema que, embora já se manifestasse nas obras de alguns cineastas, vai ganhar mais força a partir dos anos de 1990. É neste momento que o documentário, especialmente, experimenta o que Català (2012) classifica como uma "virada subjetiva" que põe em evidência os filmes ensaísticos e autobiográficos (cujas características se misturam, em muitos casos). Na próxima seção, são apresentadas algumas contribuições mais recentes, inclusive do próprio Català, no sentido de tentar compreender as manifestações do ensaio no cinema.

\section{Algumas tentativas recentes de aproximação teórica ao ensaio fílmico}

Se o mapeamento anterior pode sugerir que o interesse pelo ensaísmo no cinema parece ter arrefecido entre as décadas de 1970 a 1990, recentemente o tema tem sido objeto de vários estudos. Pesquisadores vêm se debruçando sobre este tipo de produção por meio dos mais diversos vieses analíticos, desde a perspectiva histórico-conceitual que busca definir, descrever e mapear o ensaio audiovisual, desenvolvida por autores como os já citados Lopate (1996), Rascaroli (2008, 2009), Català (2005, 2014) e Weinrichter (2007), até o estudo do ensaio fílmico como um braço do documentário, como é o caso de Renov (2005), no âmbito nacional, Lins (2008a, 2008b), Feldman (2012), Rebello (2012) e Gervaiseau (2015), que vêm se ocupando de uma tendência ensaístico-reflexiva verificada no documentário brasileiro contemporâneo.

O texto de Lopate de 1996 se tornaria uma espécie de marco temporal para o estudo recente dos ensaios audiovisuais. Intitulado In Search of the Centaur: The Essay-Film, é um artigo totalmente calcado na relação entre o ensaio fílmico e a literatura, a ponto de o autor afirmar (embora advirta de antemão que se trata de uma proposição questionável), que um filme-ensaio deve obrigatoriamente conter palavras, na forma de texto falado, subtítulo ou intertítulo: "Digam o que quiserem sobre a visualidade ser o núcleo da coisa, mas não posso aceitar um fluxo puro e completamente silencioso de imagens como constitutivo de um discurso ensaístico." (Lopate, 1996: 253, tradução nossa). 
O autor apresenta uma prescrição das características que permitiriam classificar um filme como ensaístico e se refere diretamente ao texto em várias delas, afirmando inclusive que deve ser bem-escrito e eloquente. A esta provocação inicial de Lopate, que em certos momentos guarda até um tom de chiste, seguiram-se esforços mais consistentes de outros autores, que serão apresentados em seguida. No entanto, é interessante observar em Lopate a valorização do texto e da palavra de uma maneira extremamente literal. Para ele, não é suficiente a existência de uma instância enunciadora que possa ser identificada no filme, que se manifeste de forma autoral e que pode ou não estar presente materialmente na obra ${ }^{6}$. Lopate considera necessária a presença do texto em sentido estrito, de preferência através de um narrador, como se o ensaio fílmico tivesse que funcionar como uma espécie de monólogo interior para a exposição de conceitos e ideias.

Já Antonio Weinrichter (2007: 12) afirma que "não existe um acordo geral sobre o que possa ser um ensaio cinematográfico" e que há quem o considere um possível horizonte para o audiovisual no século XXI, um fruto da era pós-moderna de confusão de fronteiras, modos e discursos. O autor aponta a contribuição de Alain Bergala, que descreve o filme-ensaio de modo muito semelhante à maneira como Theodor Adorno pensa o ensaio na literatura, sugerindo que estas diferentes manifestações compartilham os mesmos princípios: "É um filme que não obedece a nenhuma das regras que regem geralmente o cinema como instituição: gênero, duração padrão, imperativo social.” (Bergala apud Weinrichter, 2007: 27, tradução nossa).

É um filme livre, segundo Bergala, que reinventa a cada vez a sua própria forma, que só valerá a ele. Questionando a posição um tanto radical de Bergala acerca da impossibilidade de uma definição para o ensaio fílmico, Weinrichter afirma:

Bergala chega a sugerir que um verdadeiro ensaio inventa não apenas sua forma e seu tema, mas também o seu referente: à diferença do documentário, que filma e organiza o mundo, o ensaio o constitui. Ou seja, não pode servir, por definiçã̃o, de modelo de nada. E a prática do cine-ensaio se reduziria a uma série de casos singulares, não só porque a instituição se nega a integrá-los em sua tradição, como porque o são, necessariamente: a única generalidade que parece possível afirmar sobre um filme-ensaio é que cada filme é... um caso particular. Vale a pena, então, esforçar-se para atribuir categoria

6. A este respeito, vale lembrar do conceito de "voz do documentário", formulado por Bill Nichols (2005), que refere-se ao discurso do filme, num âmbito mais geral, cujo direcionamento se pode inferir através da análise do todo de uma determinada obra, e não necessariamente da fala de um personagem ou narrador. Muitas vezes, a voz do documentário fica explícita na "voz de Deus", na fala de um narrador que expõe um ponto de vista que o realizador pretende transmitir, mas esta não é uma regra. Por exemplo, documentários de teor observacional também têm a sua voz, que corresponde muito mais uma intencionalidade ou um viés presente na tessitura da obra do que ao que é dito por um narrador ou personagem. 
de gênero ao que é essencialmente excêntrico, fronteiriço, 'não-genérico' e singular? (Weinrichter, 2007: 27, tradução nossa).

Ainda que diante da dificuldade de conceituar as variadas práticas ensaísticas, os autores têm empreendido esforços no sentido de identificar traços deste tipo de produção, deparando-se sempre uma espécie de dilema, que também aparece na fala de Bergala: alguma definição fechada pode ser aplicada a um tipo de obra que é, por natureza, fugidia e livre de amarras de gênero? Weinrichter tenta fugir de uma classificação fácil e bastante sedutora de que o ensaio seria todo texto que não "cabe" em nenhum outro lugar, e sinaliza que "podemos pensar que esta dificuldade de encaixe é o que o define como categoria à parte; mas estaríamos caindo numa definição tão atrativa (por transgressora) como imprecisa e negativa" (2007: 24, tradução nossa). Català, por sua vez, esboça o que chama de "estrutura básica" do ensaio fílmico: "[...] uma reflexão por meio de imagens, realizada através de uma série de ferramentas retóricas que se constroem ao mesmo tempo em que o processo de reflexão." (Català, 2005: 133, tradução nossa).

Se parece problemático classificar o ensaio fílmico como gênero cinematográfico, uma vez que afirma-se tão livre que não admite se configurar como tal, pode ser pertinente pensá-lo como forma fílmica e mapear os gestos formativos e os dispositivos criativos que perpassam um determinado conjunto de obras, já que tanto os estudos sobre o ensaio na literatura quanto no cinema assinalam uma preponderância das questões estético-formais em todo discurso que se apresenta de modo ensaístico. Este me parece um caminho natural: se o ensaio é um discurso que produz os seus próprios dispositivos, as questões estético-formais vão necessariamente ganhar força. Que forma, entretanto, seria esta, se Bergala diz que ela é própria de cada filme-ensaio e só valeria a ele?

Ao apresentar a reflexão por meio das imagens, a forma-ensaio não propõe meramente um jogo metalinguístico ou autorreflexivo. A subjetividade do autor está posta sempre de modo bastante evidente, mas não se trata exatamente de uma escrita de si (como faz o documentário autobiográfico) ou de uma reflexão "ilustrada" por imagens (como é expediente comum do documentário expositivo), mas sim de inscrever a reflexão nas próprias imagens, de pensar por e com imagens.

Embora uma parte numerosa da bibliografia disponível a respeito do ensaísmo no audiovisual se refira a um tipo de "cinema de pensamento", estas contribuições muitas vezes acabam abordando menos o ato de pensar com imagens e mais o de fazer pensar sobre o que as imagens nos mostram, e entre 
estes dois âmbitos há uma diferença importante. Pensar cinematograficamente difere de ilustrar um pensamento com imagens.

O ensaio fílmico não é simplesmente autorreflexivo, embora o seja de maneira imprescindível, segundo Català. Numa tentativa de diferenciá-lo do documentário autorreflexivo, o autor afirma que este se limita a colocar em evidência os dispositivos, não necessariamente a explorá-los, e também não se dedica a utilizar os resultados desta exploração como ferramenta hermenêutica. Enquanto isso:

A estrutura característica do filme-ensaio é híbrida, uma estrutura que vai do pessoal-biográfico (dividido em experiências pessoais, sonhos, opiniões) ao reflexivo, filosófico, artístico, etc. Tem ao menos dois níveis, portanto: um através do qual persegue um objeto, um tema (ou vários) e outro por meio do qual este tema se expressa esteticamente: o entremeado, o caráter híbrido se expressa ao mesmo tempo em que o seu próprio tema. A forma sobe claramente à superfície [...]. (Català, 2005: 145, tradução nossa).

Català afirma que a história do cinema documental é marcada por uma evolução de mentalidades, de modos de colocar o cinema a serviço da exposição de um "real" e de crer nas possibilidades desta exposição. O que se nota hoje, segundo o autor, é um esgotamento dos dispositivos convencionais do cinema (em diversos aspectos, das narrativas ao modo mais tradicional de exibição dos filmes), de maneira que "o dispositivo cinematográfico não basta para expressar por si só a complexidade do real e é necessário fazer algo mais" (Català, 2012: 17). Neste caso, o "algo mais" seria a criação de dispositivos cada vez mais complexos e necessariamente ensaísticos, pois colocariam em xeque justamente o fato de que o dispositivo cinematográfico e os meios narrativos clássicos, por si só, não são suficientes.

Identifico também em José Moure outra interessante perspectiva, que começa por questionar se haveria uma obra fundadora do cinema de ensaio, como há no caso do ensaio literário (os Ensaios de Montaigne). Num texto chamado Essai de définition de l'essai au cinema (2004), Moure acaba localizando as origens do ensaio fílmico em Orson Welles e Roberto Rossellini e enuncia duas proposições: 1) o ensaio como um projeto de cinema, e 2) o ensaio como um projeto da modernidade. Em relação ao primeiro ponto, o autor afirma que, antes de existir como realidade fílmica, o ensaio existe como projeto de filme inacabado e como projeto de um cinema futuro: "Invoca a ideia do ensaio de modo a prestar uma homenagem à sétima arte, e de apostar no seu futuro, na sua capacidade de rivalizar com a literatura no terreno do pensamento" (Moure, 2004: 26, tradução nossa).

Sobre o ensaio como projeto da modernidade, Moure busca na Carta à Rossellini, escrita por Jacques Rivette por ocasião do filme Viagem à Itália, 
e publicada nos Cahiers du Cinéma em 1955, uma formulação que associa efetivamente o cinema ao ensaio. Rossellini, tal qual Montaigne, é ele mesmo a matéria do seu filme. Segundo Rivette, Viagem à Itália:

[...] oferece enfim ao cinema, até agora obrigado a contar histórias, a possibilidade do ensaio. O ensaio, há mais de cinquenta anos, é a língua mesma da arte moderna; é a liberdade, a inquietude, a exploração, a espontaneidade; enterrou, gradualmente - Gide, Proust, Valery, Chardonne, Audiberti - o romance debaixo de si; desde Manet e Degas, reinou sobre a pintura e lhe deu seu modo apaixonado, seu senso de busca e de proximidade. Temos, pois, um filme que reúne: [...] ensaio metafísico, confissão, diário de bordo, diário íntimo. (Rivette apud Moure, 2004: 32, tradução nossa).

Moure afirma, então, que "se a forma do ensaio no cinema se inscreve em alguma filiação, é aquela da modernidade, das formas que pensam" (2004: 32, tradução nossa). O germe do ensaísmo no cinema estaria, para o autor, na fundação do cinema moderno, por isso a referência constante a Rossellini e Welles. E especialmente no que se refere a Viagem à Itália, estariam postos ali todos os princípios do ensaio, que se exerce como pensamento, ponderação, exame, teste, experimentação, "tateamento", experiência do mundo, da vida e de si. Também é destacada a figura de Godard, a quem Moure considera o cineasta que mais levou a cabo a proposta de elaborar um "pensamento-cinema", ainda que, em sua tentativa de definição, Moure resvale justamente na afirmação do ensaio fílmico por exclusão de outras formas, e embora para o próprio autor uma pergunta permaneça sem resposta conclusiva: "Que critérios, temáticas ou formas permitem-nos distinguir os filmes que poderiam ser incluídos no seio da categoria não-instituída do ensaio?". (Moure, 2004: 35, tradução nossa).

Moure (2004) sugere que se deva partir da premissa de que os filmes ensaísticos convergem para um pensamento reflexivo no tratamento de um determinado tema, objeto ou questão, e seria necessário, assim, distinguir ensaios sobre temas tão distintos quanto política (como Vento do Leste, de Godard, 1970); arte (O Mistério de Picasso, de Henri-Georges Clouzot, 1955); cinema (Uma viagem com Martin Scorsese através do cinema americano, de Martin Scorsese, 1995); história (Allemagne 90 neuf zero, Godard, 1990) ou ainda objetos e lugares (Mediterranée, de Jean-Daniel Pollet e Volker Schlöndorff, 1963).

Ainda que os escritos de Moure ajudem a lançar luz sobre alguns aspectos do ensaio e façam parte de um dos mais citados livros dedicados ao assunto ${ }^{7}$, é necessário apontar uma ressalva: o autor estabelece um tipo de hierarquia que

7. O já mencionado L'Essai et le cinema (2004), organizado por Liandrat-Guigues e Gagnebin. 
considero duvidosa entre o ensaio fílmico e outras formas expressivas, como se se tratasse de uma evolução das linguagens da literatura e do cinema que confluiu numa nova forma, melhor ou superior.

Outra consistente contribuição recente - essa disponível no Brasil - é o livro O filme-ensaio: desde Montaigne e depois de Marker (2015), de Timothy Corrigan. O autor parte de duas premissas principais: a primeira é de que cabe ao ensaio fílmico um lugar de autonomia em relação ao documentário e ao cinema experimental, o que significa que as tentativas de pensar o ensaio fílmico inserido na historiografia do cinema limitam as possibilidades de reconhecimento do fenômeno em toda a sua capacidade de intervenção crítica. A segunda é de que o filme-ensaio "focaliza questões centrais na relação historicamente variada e multidimensional entre o cinema e a literatura" (Corrigan, 2015: 10), nos convidando a pensar esse vínculo a partir de outros parâmetros que não sejam as interações entre o cinema e a ficção narrativa, o teatro dramático ou a poesia, e buscando privilegiar especialmente a relação entre verbal e visual (e não aspectos como a adaptação).

Interessa a Corrigan considerar a inflexão ensaística no cinema e através do cinema, tomando o ensaístico como um encontro entre o eu e o domínio público. Assim, o filme-ensaio pode ser pensado como linguagem que mobiliza diversas matérias expressivas e traz ao primeiro plano uma voz reconhecível, uma expressão pessoal. No entanto, mesmo que essa expressão pessoal eventualmente assuma um tom autobiográfico, ela não é confessional, uma vez que o ensaio pressupõe a manifestação de um sujeito que se coloca em abertura para o mundo, numa espécie de ação performativa do eu, caracterizando-se como "prática que renegocia pressupostos a respeito da objetividade documentária, da epistemologia narrativa e da expressividade autoral dentro do contexto determinante da heterogeneidade instável de tempo e lugar." (Corrigan, 2015: 10).

Para Corrigan, parte da força do ensaio estaria na sua capacidade de questionar ou redefinir pressupostos representacionais e abraçar a sua própria condição antiestética, ao mesmo tempo em que os desafios para definir o filmeensaio são os motivos mesmos que o tornam tão inventivo:

A meio caminho da ficção e da não-ficção, das reportagens jornalísticas e da autobiografia confessional, dos documentários e do cinema experimental, eles são, primeiro, práticas que desfazem e refazem a forma cinematográfica, perspectivas visuais, geografias públicas, organizações temporais e noções de verdade e juízo na complexidade da experiência. (Corrigan, 2015: 9-10).

Identifico uma diferença fundamental entre os escritos iniciais de Richter, Astruc, Rivette e Burch, produzidos entre as décadas de 1940 e 1960, e as teorizações recentes de Lopate, Català, Weinrichter e Corrigan após os anos de 
1990. Enquanto os primeiros pareciam preocupados em notar uma nova vocação para o cinema, em vislumbrar o potencial cinematográfico de exposição de ideias, formulações intelectuais e pensamento, na atualidade os autores partem de algo que é dado: a vocação ensaística do cinema existe e se manifesta de formas muito distintas entre si, o que talvez torne mais prolífico analisar cada filme-ensaio caso a caso, ao invés de tentar instituí-lo como gênero.

Há algo que também surge como discurso de fundo nos autores que têm pesquisado o tema recentemente: a negação de uma episteme própria ao ensaio fílmico. Ela se manifesta não apenas quando surgem, em seus escritos, tentativas de definição do ensaio a partir de negativas, mas principalmente quando eles afirmam efetivamente que uma definição muito fechada contraria a própria natureza do fenômeno. Este aparente paradoxo que cerca o ensaio fílmico será explorado na próxima e última seção.

\section{Em busca de um conceito}

Marcado pelos princípios da liberdade e da experimentação, o ensaio - de forma ampla, não apenas no cinema - se apresenta como um lugar sem mapa, uma forma que passeia pela arte e pela ciência e, muitas vezes rejeitada no campo científico, costuma ser considerada imprecisa e excessivamente subjetiva. Numa releitura do clássico texto de Adorno sobre o ensaio, Cássio Hissa e Adriana Melo o afirmam como:

Uma pausa apenas, em vez da pretensão de um acabamento definitivo. Um silêncio eloquente. $\mathrm{O}$ eterno devir da linguagem, dos conceitos de um mundo permanentemente em construção. Espaço de algo a ser continuamente experimentado e, portanto, transmutado, transcriado. Lugar sem mapa cujo percurso, desenhado e redesenhado por um incessante devir, redefine trajetórias de partida e de chegada, aproximando fim e início, desordenando e desalojando significados culturalmente construídos e estabelecidos. (Hissa, Mello, 2011: 251).

As formulações a respeito do ensaísmo no cinema são, naturalmente, bastante devedoras das teorizações acerca do ensaio literário, sobretudo as contribuições de Adorno e também de Georg Lukács. De Adorno, a afirmação da fragmentação e a renúncia às certezas, bem como o descompromisso com uma expressão excessivamente cartesiana do pensamento:

O ensaio não apenas negligencia a certeza indubitável, como também renuncia ao ideal dessa certeza. Torna-se verdadeiro pela marcha de seu pensamento, que o leva para além de si mesmo, e não pela obsessão em buscar seus fundamentos como se fossem tesouros enterrados. (Adorno, 2008: 30).

De Lukács (1974), destacam-se as observações sobre sobre o caráter errático e anti-dogmático do ensaio, definido pelo autor um tipo de julgamento em 
que o essencial não é o veredito ou a distinção de valores, mas sim o processo de julgar; um saber que, ao contrário de outros, a exemplo do conhecimento científico, não busca superar os anteriores.

Michel de Montaigne, no texto Do arrependimento, parte do Livro III dos Ensaios, evoca imagens que também me parecem bastante pertinentes para pensar o ensaio e a própria sensação de desorientação que ele provoca:

O mundo é movimento; tudo nele muda continuamente; a terra, as montanhas do Cáucaso, as pirâmides do Egito, tudo participa do movimento geral e do seu próprio; e a imobilidade mesma não passa de um movimento menos acentuado. Não posso fixar o objeto que quero representar: move-se e titubeia como sob o efeito de uma embriaguez natural. Pinto-o como aparece em dado instante, apreendendo-o em suas transformações sucessivas, não de sete em sete anos, como diz o povo que mudam as coisas, mas dia por dia, minuto por minuto. É pois no momento mesmo em que o contemplo que devo terminar a descrição; um instante mais tarde não somente poderia encontrarme diante de uma fisionomia mudada, como também minhas próprias ideias possivelmente já não seriam as mesmas. (Montaigne, 2016: 760).

Se, em Montaigne, o ensaio designa uma experiência e, para Henri Gervaiseau (2015), essa experiência é vivida na duração, como descoberta empírica de si no exercício de relação com o mundo, uma pergunta inevitável surge ao pensar sobre o ensaio no cinema: como colocar essa experiência em imagens e sons?

A metáfora de deriva que emana da própria ideia de ensaio fílmico me fez assumir o fenômeno como algo situado em uma dimensão sempre processual, e pensá-lo como abstração e radicalidade. Filio-me a Francisco Elinaldo Teixeira, quando questiona se o ensaio fílmico constituiria um quarto domínio das imagens e afirma que "O ensaio é um outro da filosofia, da literatura e mais recentemente do cinema. Não um 'outro de si', mas uma alteridade radical" (Teixeira, 2015: 13).

Penso ser proveitoso pensar o ensaio fílmico não como uma "transcrição" ou tradução cinematográfica da tradição do ensaio literário ou filosófico, mas como metáfora epistemológica que aponta a construção de um tipo específico de saber a respeito do mundo histórico, construído com imagens e por meio de imagens, passível de ser identificado em algumas obras, a exemplo de Toda a memória do mundo (1956), de Resnais; Carta da Sibéria (1975) e O fundo do ar é vermelho (1977), ambos de Marker; As estátuas também morrem (1953), parceria de Resnais e Marker; História(s) do cinema (1988-1998), de Godard, Os catadores e eu (2000) e As praias de Agnès (2008), ambos de Varda, ou ainda na obra de Farocki, desde em Imagens do mundo e inscrições da guerra (1989) e Videogramas de uma revolução (1992) até videoinstalações mais recentes em que discute a imagem gerada por computador e os jogos eletrônicos, 
como Serious Games, de 2009/2010. Também é possível mencionar, no caso do Brasil, experiências como os filmes Santiago (2006) e No Intenso Agora 2017 (de João Moreira Salles), ou mesmo obras de Eduardo Coutinho, documentarista cuja obra guarda uma forte sensibilidade ensaística.

Apesar de compartilhar da visão de que a validade de um conceito fechado para o ensaio fílmico é questionável (e que, penso eu, talvez seja mais adequado tratar o ensaísmo como um gesto, um anseio, uma sensibilidade ou uma inflexão), considero produtivo delimitar uma noção que possa se somar aos esforços de consolidação dos estudos em torno do fenômeno. Parto da premissa de que pode ser útil "dissociar" o estudo do ensaio fílmico da literatura e aproximá-lo com mais ênfase dos campos das artes e do audiovisual. Não se trata de negar o que possa haver de literário no ensaio fílmico, ou de colocar cinema e literatura em oposição, uma vez que o próprio termo "ensaio" provavelmente remeterá sempre à literatura, mas abordar o filme-ensaio em seus aspectos audiovisuais e não em sua possível vinculação à literatura. Reconheço que há uma relação inerente entre ensaio fílmico e literatura e esta relação é sempre referencial, mas não necessariamente valorativa.

Este jogo de forças contraditórias (definir ou não definir?) aparece constantemente nos estudos trazidos à tona nesse artigo. Voltar a isso com tanta frequência pode sugerir que a conceituação do ensaio audiovisual gira em círculo e, para cada dois passos à frente numa tentativa de delimitação, dá-se um passo atrás com reconsiderações, parênteses, reticências e um certo receio de fazer afirmações muito assertivas. A impressão pode ser verdadeira, mas há razão para tamanho cuidado com o ensaio como objeto de estudo - afinal, uma definição que desrespeite a natureza do fenômeno é tão inútil quanto a ausência total de definição ${ }^{8}$. Este paradoxo é abordado por Català, quando admite a necessidade operativa de sistematizar um conceito, mas ao mesmo tempo assume as suas inerentes limitações:

Se o filme ensaio é complexo [...], não podemos supor que nenhuma operação definidora, isto é, reducionista, será capaz de abarcá-lo em suas múltiplas dimensões. Por outro lado, sua própria existência - que se produz tanto por eliminação das formas limítrofes quanto pela assimilação delas, com as quais se combina e das quais toma emprestados muitos elementos - parece nos obrigar a efetuar algum tipo de delimitação se quisermos seguir trabalhando em terreno seguro. (Català, 2014: 155, tradução nossa).

Se parece difícil apresentar um conceito fechado para o ensaio fílmico, um tanto mais fácil é identificar o seu princípio norteador maior: apresentar-se como práxis cinematográfica que, carecendo conscientemente de autoridade

8. De um ponto de vista epistemológico, este cuidado se justifica na formulação de qualquer conceito no interior de um campo em construção. 
epistemológica, propõe diferentes movimentos e modos de pensar o mundo e os próprios meios visuais e audiovisuais. Busca, sobretudo, ressaltar um aspecto que não é novo, mas aparece aqui destacado: os tipos de discursos a respeito do mundo histórico produzidos pelas imagens não são apenas da ordem da representação mimética (e nem o ensaio busca superá-la). O cinema de ensaio também se configura como discurso sobre o mundo histórico, mas sua organização estético-discursiva não obedece aos padrões do documentário e nem da representação ficcional clássicos, pois aciona procedimentos e dispositivos distintos, com objetivos também distintos, valorizando a dimensão da experiência e do processual. Como afirma Ismail Xavier:

Falar em filme-ensaio envolve um posicionamento da crítica diante do seu objeto como um experimento, exame de uma questão sem o apelo às regras fechadas de um método, uma experiência intelectual mais aberta em que o pensamento se arrisca em terrenos onde a exatidão é impossível. E envolve também o senso de que tal exame responde à insistência de uma questão no espaço da cultura e a uma busca de apreensão do objeto em sua variabilidade, assumindo a legitimidade do transitório como foco de atenção. Há, na linhagem secular do ensaio, um impulso anti-sistêmico e a marca da subjetividade. (Xavier, 2014: 33).

O que as obras de caráter ensaístico sugerem é que as imagens, em suas múltiplas formas de apresentação, podem ter outras vocações, como evocar e materializar de modo mais premente uma forma de pensamento; podem oferecer outras experiências além daquelas derivadas do "valor de verdade" da fotografia documental ou mesmo do cinema documentário. Podem, também, distanciar-se da experiência cinematográfica considerada clássica, que se tornou hegemônica já nos anos de 1920 e assim permanece até hoje.

A prática do ensaísmo diz respeito não apenas a questões de estilo, mas a um certo anseio e a uma intencionalidade, a procedimentos de exposição de um pensamento, de um modo de estar no mundo e, em grande parte dos casos, também de uma reflexão metalinguística acerca dos próprios meios de registro e exibição das imagens. Podem ser ensaísticos, assim, diferentes tipos de obras que lidam com as imagens e o audiovisual. Mais do que criar uma categoria a partir da qual seria possível rotular alguns filmes como ensaios e outros não, creio ser mais producente pensar numa inflexão ensaístico-reflexiva da qual distintas obras podem ser dotadas, e em diferentes graus.

Assim, considero ensaísticos em algum nível desde filmes que cabem perfeitamente no cânone do documentário, como Cabra Marcado para Morrer (1984), por sua capacidade de aglutinar numa só obra o histórico, o biográfico, o autobiográfico, o metalinguístico e o autorreflexivo, até um trabalho recente como a videoinstalação Parallel I-IV (2012-2014), de Harun Farocki, pelos 
questionamentos sobre as formas de produção e recepção das imagens geradas por computador pelos indivíduos e o questionamento sobre o modo como as imagens de síntese afetam a sua percepção em relação à realidade.

São propostas radicalmente distintas e sem nenhuma ligação aparente, mas que foram colocadas em relação aqui de modo proposital, para contribuir com a exposição da ideia de ensaio audiovisual. Esta noção, por sua vez, independe de gênero narrativo ou suporte de produção e não passa por identificar traços comuns num sentido de repetição, mas sim de mapear tentativas de produzir o que venho chamando de pensamento audiovisual, de pensar por e com imagens e de alcançar através das obras um aprofundado nível de reflexão a respeito de questões do mundo histórico.

Compreendo o ensaio fílmico, na linha de Català e Bergala, como um tipo de obra que produz não apenas um discurso, mas também o dispositivo do discurso, que lhe é próprio e, muitas vezes, único. Assim, a forma do ensaio fílmico pode ser sempre pensada a partir de diferentes gestos constituintes e a partir também da noção de dispositivo, que faz com que as obras ensaísticas tragam ao centro da discussão não apenas questões temáticas ou metalinguísticas, mas também as suas próprias condições de possibilidade enquanto produtos audiovisuais.

A prática ensaística surge como uma maneira de promover deslocamentos. Ainda que os dispositivos variem de uma obra a outra e inviabilizem o ensaio como categoria fechada, alguns deslocamentos são comuns, sendo o principal deles a criação de um modo próprio (e muitas vezes único a cada filme) de fazer asserções a respeito do mundo histórico, quando o documentário ou a ficção baseados no estatuto da representação parecem não ser suficientes. Trata-se de uma consciência dos limites da representação, e não exatamente de uma crítica a ela. E a partir do momento em que os realizadores exploram o dispositivo, eles também provocam os espectadores a contemplar as imagens e os discursos engendrados por elas de um modo diferente. O dispositivo aparece, assim, transformado em ferramenta hermenêutica.

O ensaio fílmico não é pensado em função apenas de aspectos internos às obras, dos seus traços imanentes, mas sim dos dispositivos criativos acionados para a sua realização. Surge como intencionalidade e gesto, como tomada de posição e lugar de afirmações sobre um modo de fazer e pensar o cinema, as imagens e o mundo. Torna central a figura do sujeito, uma vez que coloca em destaque o dado autoral. Isso se dá uma vez que o ensaio audiovisual faz emergir a figura do autor como sujeito que se posiciona por meio de obras que são, muitas vezes, "filmes de teses", mas também na medida em que boa parte das obras ensaísticas guardam um forte teor humanista. 


\section{Considerações finais}

Buscar um lugar histórico mais refinado para os filmes-ensaio significa, para Corrigan (2015), situar-se em lugares escorregadios, entre a tentativa de categorização e o cuidado com a natureza antigenérica própria desta forma de expressão; entre o rigor em busca de uma definição e o caráter de "método não metódico" daquilo a que o autor se refere como um "gênero de experiência". Escrever sobre o ensaísmo e os filmes-ensaio exigiria mais autoconsciência do que de costume na escrita acadêmica e histórica e o caminho trilhado por Corrigan passa por assumir que o filme-ensaio opera com sobreposições múltiplas, diversas e inevitáveis, ou seja, que existem especificidades textuais dos filmes que atestam seu caráter singular, mas que ao mesmo tempo é possível pensar em um conjunto de modos específicos situados em uma história maior do ensaio.

Se um mapeamento de traços de obras audiovisuais tidas como ensaísticas vai permitir identificar como recorrências o uso de material de arquivo, o dado autorreflexivo, a reflexão sobre o cinema imbricada ao mundo histórico e a subjetividade, é importante ter claro também que esses traços surgem de formas muito distintas nos filmes e que eles não são suficientes para que uma obra seja um ensaio. Não se trata, então, da repetição de convenções estilístico-formais e sim do modo como elas são convocadas na expressão de uma voz pessoal reconhecível que se coloca em relação de abertura com o mundo, que reflete as grandes questões éticas, estéticas e políticas.

\section{Referências bibliográficas}

Adorno, T. (2008). O Ensaio como Forma. São Paulo: Editora 34.

Arthur, P. (2003). Essay questions: from Alain Resnais to Michael Moore. Film Comment, 1(39): 58-62. Nova Iorque. Disponível em: http://artsites .ucsc.edu/faculty/gustafson/film\%20223/ArthurEssayQuestions.pdf

Astruc, A (2010). Nacimiento de una nueva vanguardia: la 'Caméra-stylo'. In J. Ramió \& H. Thevenet (org.), Textos y Manifiestos del Cine: Estética. Escuelas. Movimientos. Disciplinas. Innovaciones (pp. 220-224). Madrid: Ediciones Cátedra.

Blüminger, C \& Wulff, C. (org.). (1992). Schreiben Bilder Sprechen: Texte zum essayistischen film. Vienna: Sonderzahl.

Burch, N. (2008). Práxis do Cinema. São Paulo: Perspectiva.

Català, J. (2005). Film-ensayo y vanguardia. In C. Torreiro \& J. Cerdán (orgs.), Documental y vanguardia (pp. 109-158). Madrid: Ediciones Catédra. 
Català, J. (2012). A estética como ato político. Entrevista a Gabriela Almeida e Jamer Mello. Em Questão (UfRGS, Online), 2(18), 15-24. Porto Alegre. Disponível em: http://seer.ufrgs.br/index.php/EmQuestao/article/view/36 $413 / 24242$

Català, J. (2014). Estética del ensayo: la forma ensayo, de Montaigne a Godard. Valência: Universitat de València.

Corrigan, T. (2015). O filme ensaio: desde Montainge e depois de Marker. Campinas: Papirus.

Feldman, I. (2012). Jogos de cena: ensaios sobre o documentário brasileiro contemporâneo. São Paulo: Tese de Doutorado, Universidade de São Paulo.

Gervaiseau, H. (2015). Escrituras e figurações do ensaio. In F. E. Teixeira (org.), O ensaio no cinema: formação de um quarto domínio das imagens na cultura audiovisual contemporânea (pp. 92-118). São Paulo: HUCITEC.

Hissa, C \& Melo, C. (2011). Sobre o ensaio. In C. Hissa (org.), Conversações: de artes e de ciências (pp. 251-275). Belo Horizonte: Editora UFMG.

Liandrat-Guigues, S. \& Gagnebin, M. (org.). (2004). L'essai et le cinema. Seyssel: Éditions Champ Vallon.

Lins, C. \& Mesquita, C. (2008a). Aspectos do documentário brasileiro contemporâneo (1999-2007). In M. Baptista \& F. Mascarello, Cinema mundial contemporâneo (pp. 157-175). Campinas: Papirus.

Lins, C. \& Mesquita, C. (2008b). Filmar o real: sobre o documentário brasileiro contemporâneo. Rio de Janeiro: Zahar.

Lopate, P. (1996). In Search of the Centaur: The Essay Film. In C. Warren, Beyond Document: Essays on Nonfiction Film (pp. 243-269). Middletown: Wesleyan University Press.

Lukács, G. (1974). Soul and Form. Cambridge: MIT Press.

Montaigne, M. (2016). Ensaios: edição integral. São Paulo: Editora 34.

Moure, J. (2004). Essai de définition de l'essai au cinéma. In S. LiandratGuigues \& M. Gagnebin (Org.). Le essai et le cinéma (pp.25-40). Seyssel: Éditions Champ Vallon.

Nichols, B. (2005). A voz do documentário. In F. Ramos (org.), Teoria contemporânea do cinema, volume II: Documentário e narratividade ficcional (pp. 47-67). São Paulo: Senac. 
Rascarolli, L. (2008). The Essay Film: Problems, Definitions, Textual Commitments. Framework: The Journal of Cinema and Media, 2(49): 24-47. Detroit. Disponível em: www.jstor.org/stable/41552525

Rascarolli, L. (2009). The Personal Camera: subjective cinema and the essay film. London: Wallflower Press.

Rebello, P. (2012). O documentário sob o risco do ensaio: subjetividade, liberdade e montagem. Rio de Janeiro: Tese de Doutorado, Universidade Federal do Rio de Janeiro.

Renov, M. (2005). Investigando o sujeito: uma introdução. In A. Labaki \& M. D. Mourão (org.), O Cinema do Real (pp. 234-257). São Paulo: Cosac Naify.

Richter, H. (2007). El ensayo fílmico. Una nueva forma de la película documental. In A. Weinrichter (org.), La forma que piensa. Tentativas en torno al cine-ensayo (pp. 186-189). Pamplona: Gobierno de Navarra, colección Punto de Vista.

Teixeira, F. E. (org.). (2015). O ensaio no cinema: formação de um quarto domínio das imagens na cultura audiovisual contemporânea. São Paulo: HUCITEC.

Weinrichter, A. (org.). (2007). La forma que piensa. Tentativas en torno al cine-ensayo. Gob. de Navarra, colecc. Pamplona: Punto de Vista.

Xavier, I. (2014). A teatralidade como vetor do ensaio fílmico no documentário brasileiro contemporâneo. Revista Aniki, l(1): 33-48. Lisboa. Disponível em: http://aim.org.pt/ojs/index.php/revista/article/view/52/html.

\section{Filmografia}

Allemagne 90 neuf zero (1990), de Jean-Luc Godard.

As estátuas também morrem (1953), de Alain Resnais e Chris Marker.

As praias de Agnès (2008), de Agnès Varda.

Cabra Marcado para Morrer (1984), de Eduardo Coutinho.

Carta da Sibéria (1975), de Chris Marker.

Crônica de um verão (1961), de Jean Rouch e Edgar Morin.

História(s) do cinema (1988-1998), de Jean-Luc Godard.

Imagens do mundo e inscrições da guerra (1989), de Harun Farocki.

Mediterranée (1963,), de Jean-Daniel Pollet e Volker Schlöndorff.

No Intenso Agora (2017), de João Moreira Salles. 
Noite e Neblina (1955), de Alain Resnais.

O fundo do ar é vermelho (1977), de Chris Marker.

O Mistério de Picasso (1955), de Henri-Georges Clouzot.

Os catadores e eu (2000), de Agnès Varda.

Os mestres loucos (1955), de Jean Rouch.

Parallel I-IV (2012-2014), de Harun Farocki.

Santiago (2007), de João Moreira Salles.

Serious Games (2009-2010), de Harun Farocki.

Toda a memória do mundo (1956), de Alain Resnais.

Uma viagem com Martin Scorsese através do cinema americano (1995), de Martin Scorsese.

Vento do Leste (1970), de Jean-Luc Godard.

Viagem à Itália (1954), de Roberto Rossellini.

Videogramas de uma revolução (1992), de Harun Farocki. 